\title{
SUBMUCOSAL PURSE-STRING SUTURE AS A TREATMENT OF LEAKAGE AROUND THE INDWELLING VOICE PROSTHESIS
}

\author{
Kristien Jacobs, MD, Pierre R. Delaere, MD, PhD, Vincent L. M. Vander Poorten, MD, PhD \\ Department of Otorhinolaryngology, Head and Neck Surgery, Leuvens Kanker Instituut, \\ University Hospitals Sint-Rafaël and Gasthuisberg, Leuven, Belgium. \\ E-mail: vincent.vanderpoorten@uz.kuleuven.ac.be
}

Accepted 4 July 2007

Published online 2 November 2007 in Wiley InterScience (www.interscience.wiley.com). DOI: 10.1002/hed.20732

\begin{abstract}
Background. Leakage around the indwelling voice prosthesis is an annoying complication of tracheoesophageal speech.

Methods. Twenty patients, who experienced peripheral leakage of the tracheoesophageal fistula, were treated with a pursestring suture. Our aim was to get the patients free of leakage without losing their voice prosthesis. The technique was considered successful if this objective was reached and unsuccessful if eventually closure of the fistula was required.

Results. Immediately after the procedure, no patients showed residual leakage. At 1 month, 2 patients experienced recurrent leakage. At a mean follow-up of 19.4 months, the method was successful in 16 patients and unsuccessful in 4 patients.

Conclusions. If peripheral leakage is not amenable to simple downsizing of the indwelling voice prosthesis, we feel the pursestring suture is the first-choice treatment because of its safety, efficiency, low cost, and ease of application. (C)2007 Wiley Periodicals, Inc. Head Neck 30: 485-491, 2008
\end{abstract}

Keywords: peripheral leakage; voice prosthesis; purse-string; sling suture; tracheoesophageal speech complications

Since the introduction of the first reliable voice prosthesis by Blom and Singer in 1979, tracheoesophageal puncture is nowadays the most widely

Correspondence to: V. L. M. V. Poorten

๑ 2007 Wiley Periodicals, Inc.

Submucosal Purse-String Suture for Indwelling Voice Prosthesis used procedure for vocal rehabilitation after total laryngectomy. ${ }^{1,2}$ Although success rates of longterm tracheoesophageal speech are $70 \%^{3}$ to $95 \%,{ }^{4}$ complications are not uncommon and range from $20 \%$ to $72 \% .^{5}$ Progressive enlargement of the tracheoesophageal fistula resulting in salivary leakage around the prosthesis and aspiration is 1 of the main serious problems, occurring in $7 \%$ to $42 \%$ of the patients. ${ }^{3-7}$

This dilation of the fistula is attributed to several factors. Some authors mention that previous radiotherapy increases the risk of fistula enlargement, ${ }^{4,7,8}$ while others say that it has no influence on complication rates.,6,9 Mechanical trauma, caused by excessive prosthesis size and weight or frequent prosthesis replacement, is 1 of the suggested yet unsubstantiated causative factors. ${ }^{7}$ Effects of downsizing prosthesis diameter and methods for prevention of yeast-induced prosthesis replacements are being investigated as measures to prevent peripheral leakage. ${ }^{10}$

In most patients, downsizing prosthesis length is an efficient way to solve the problem. ${ }^{2}$ For patients who had satisfactory speech results with the voice prosthesis before the leakage and could not be helped by downsizing, several techniques have been applied to maintain the tracheoesopha- 
geal fistula. The most widely used procedures are temporary removal of the prosthesis to allow the fistula to shrink ${ }^{6,8,11}$ and cauterizing the fistulous tract with silver nitrate or by electrocautery to help in fistula narrowing. ${ }^{11,12}$ Gax-collagen (Collagen Corp., Palo Alto, CA), ${ }^{13}$ Hylaform (Genzyme Corporation, Cambridge, UK, and Inamed Aesthetics, Santa Barbara, CA) ${ }^{14}$ autologous fat ${ }^{15,16}$ or Bioplastique (Uroplasty BV, Geleen, The Netherlands $)^{17-19}$ injection into the fistula wall to increase its thickness, local injection of granulocyte-macrophage colony stimulating factor ${ }^{20}$ and application of a submucosal purse-string suture are more recent techniques. ${ }^{2,21}$ When none of these methods is successful, the only option is closure of the tracheoesophageal fistula. Once the prosthesis is removed, spontaneous closure occurs in the minority of the cases. If the fistula does not close spontaneously, surgical closure is indicated, occasionally with muscular or dermal graft interposition. ${ }^{11,22-24}$ Repuncture afterward is possible. ${ }^{1,17}$

Recently, a submucosal purse-string suture around the fistula has often been applied. ${ }^{2}$ Leakage is assumed to be stopped initially by application of the suture; and subsequent fibrosis as a result of the reaction of the tissue to the suture material is suggested to prevent further leakage. ${ }^{21}$ The aim of this study was to evaluate the efficiency of this procedure in a series of 20 patients and to compare it with success rates of other techniques.

\section{PATIENTS AND METHODS}

From 2001 until 2005, 21 patients (19 men and 2 women) with peripheral leakage of the voice prosthesis were considered for treatment with a submucosal purse-string suture in our hospital. In 1 of the 21 patients, the placement of the suture was impossible because the stoma was too small. $\mathrm{He}$ was excluded for further statistics. In total, 30 purse-string sutures were applied in 20 patients. Mean follow-up was 19.4 months (range, 0.9 to 54.9). To give some idea of the relative frequency of the occurrence of peripheral leakage, it may help to know that during that same period, 211 patients underwent a total laryngectomy in our department.

All the patients were smokers, with an average smoking history of 34 pack-years. Twelve patients were addicted to alcohol. Mean alcohol consumption in these patients was 12 units a day. Thirty percent had comorbidity such as hypertension or diabetes. Mean age at diagnosis was 58 years.

All patients underwent a total laryngectomy because of a squamous cell carcinoma. Eight patients had initially been treated with radiation therapy (dose ranging from 50 to 70 Gray locally and 46 to 70 Gray regionally), but subsequently needed a total laryngectomy because of recurrent disease. The other patients received postoperative radiotherapy (dose ranging from 50 to 70 Gray locally and 50 to 70 Gray regionally). More details on tumor localization and surgical procedures are displayed in Table 1.

In 17 patients, the voice prosthesis was inserted at the time of laryngectomy, and 3 patients underwent secondary tracheoesophageal puncture. The number of voice prosthesis insertions before the suture sling ranged from 2 to 71 (mean, 13). One patient used a Provox1 (Atos Medical, Hörby, Sweden), and all the others used a Provox2 (Atos Medical) voice prosthesis at the time of intractable leakage.

When peripheral leakage occurred, downsizing of the voice prosthesis was tried first. The delay between tracheoesophageal puncture and the occurrence of peripheral leakage intractable by downsizing varied from 2.7 to 115.9 months (mean, 39.7 months).

In all patients, a clinical examination was carried out first to assess the peripheral leakage and to exclude any defect of the voice prosthesis itself (central leakage) or recurrent disease causing the problem. Leakage was confirmed when upon swallowing some water the liquid was observed to pool around the voice prosthesis. Patients received a purse-string suture 1 to 232 days after observation of untreatable peripheral leakage.

Recurrent (peripheral or both peripheral and central) leakage after the purse-string suture was in most cases treated by inserting a new voice prosthesis (mostly shorter, in 1 case longer). In 1 patient, removal of some granulation tissue solved the problem. Two patients were immediately treated with a second purse-string suture. Three patients had their fistula closed after recurrence of the peripheral leakage.

Surgical Procedures. The suture slings were applied by the same surgeon (VVP) in all the patients. The procedure can be performed with the patient under local anesthesia. Yet $55 \%$ of the purse-string sutures were placed with the patient under general anesthesia, mostly because of tech- 


\begin{tabular}{|c|c|c|c|c|c|}
\hline Patient & Tumor localization & Piriform sinus involvement & Therapy & Neck dissection & Radiation therapy \\
\hline 1 & Supra & + & $\mathrm{TL}+\mathrm{PP}+\mathrm{PMF}$ & Unilateral & Postop \\
\hline 2 & gl + supra & - & $\mathrm{TL}$ & Unilateral & Preop \\
\hline 3 & trans & + & $\mathrm{TL}+\mathrm{PP}+\mathrm{PMF}$ & Bilateral & Postop \\
\hline 4 & gl + supra & + & $\mathrm{TL}+\mathrm{PP}+\mathrm{PMF}$ & Bilateral & Preop \\
\hline 5 & Trans & + & $\mathrm{TL}+\mathrm{PP}+\mathrm{PMF}$ & Unilateral & Postop \\
\hline 6 & Trans & + & $\mathrm{TL}+\mathrm{PP}+\mathrm{PMF}$ & Bilateral & Preop \\
\hline 7 & $g l+s u b$ & - & $\mathrm{TL}$ & Bilateral & Postop \\
\hline 8 & $g l+$ sub & - & $\mathrm{TL}$ & Bilateral & Postop \\
\hline 9 & $g l+$ supra & + & $\mathrm{TL}+\mathrm{PP}+\mathrm{PMF}$ & Unilateral & Preop \\
\hline 10 & $g l+s u b$ & - & $\mathrm{TL}$ & No & Postop \\
\hline 11 & $g l+$ supra & + & $\mathrm{TL}+\mathrm{PP}+\mathrm{PMF}$ & Bilateral & Postop \\
\hline 12 & Supra & + & $\mathrm{TL}+\mathrm{PP}+\mathrm{PMF}$ & Unilateral & Preop \\
\hline 13 & gl + supra & + & $\mathrm{TL}+\mathrm{PP}+\mathrm{RF}$ & Bilateral & Preop \\
\hline 14 & Supra & + & $\mathrm{TL}+\mathrm{PP}+\mathrm{PMF}$ & Unilateral & Preop \\
\hline 15 & Trans & - & $\mathrm{TL}$ & Bilateral & Postop \\
\hline 16 & $\mathrm{gl}$ & - & $\mathrm{TL}+\mathrm{PP}+\mathrm{RF}$ & Unilateral & Preop \\
\hline 17 & Trans & + & $\mathrm{TL}+\mathrm{PP}+\mathrm{PMF}$ & Unilateral & Postop \\
\hline 18 & Supra & - & $\mathrm{TL}$ & Bilateral & Postop \\
\hline 19 & gl + supra & - & $\mathrm{TL}$ & Unilateral & Postop \\
\hline 20 & gl & - & $\mathrm{TL}$ & Unilateral & Postop \\
\hline
\end{tabular}

Abbreviations: supra, supraglottic; TL, total laryngectomy; PP, partial pharyngectomy; PMF, pectoralis major flap; postop, postoperative; gl, glottic; preop, preoperative; trans, transglottic; sub, subglottic.

nical access problems (the fistula situated too deep in the stoma, stoma too narrow). No antibiotic prophylaxis was administered.

In 18 patients, a Mersutures (Johnson \& Johnson, New Brunswick, Canada) 2/0 or $3 / 0$ was used for the first suture sling; in the other 2 patients, a Prolene (Johnson \& Johnson) 2/0 and 3/0 suture. The old voice prosthesis remained in situ throughout the procedure and was grasped with a clamp in order to modify the position of the tracheoesophageal septum according to the surgeon's needs. After making a small incision in the tra-
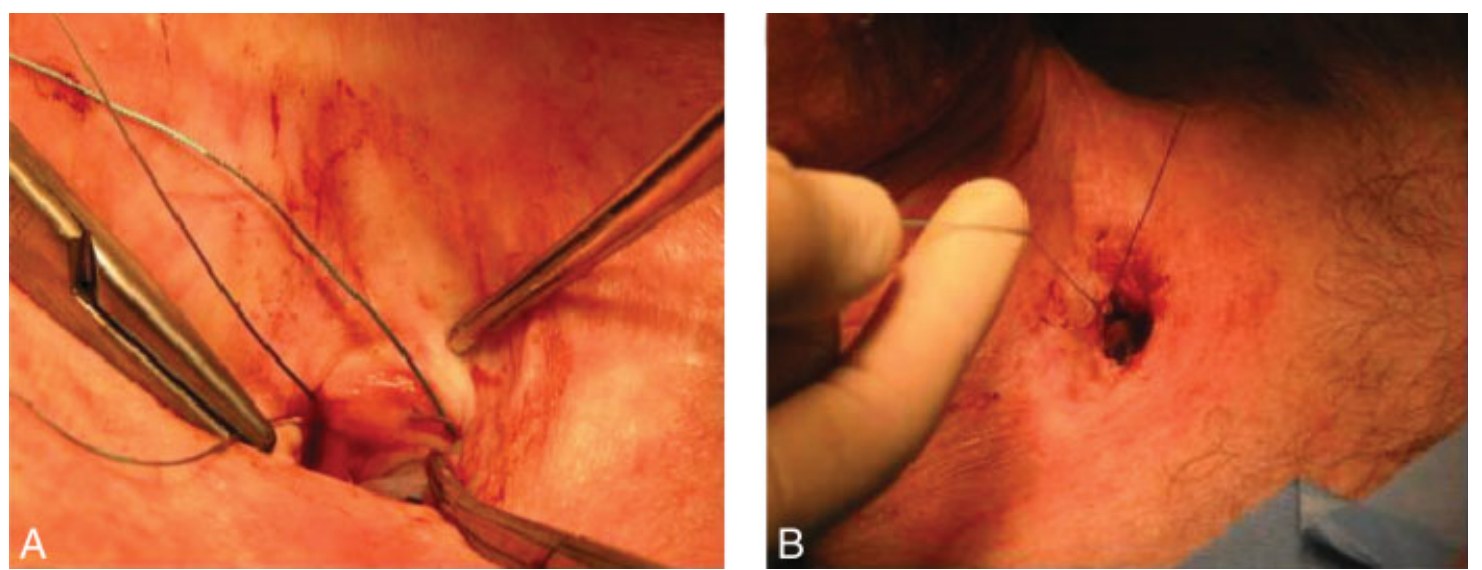

FIGURE 1. (A) Reinsertion of the needle where it has come out. (B) The knot is tied. [Color figure can be viewed in the online issue, which is available at www.interscience.wiley.com.] 


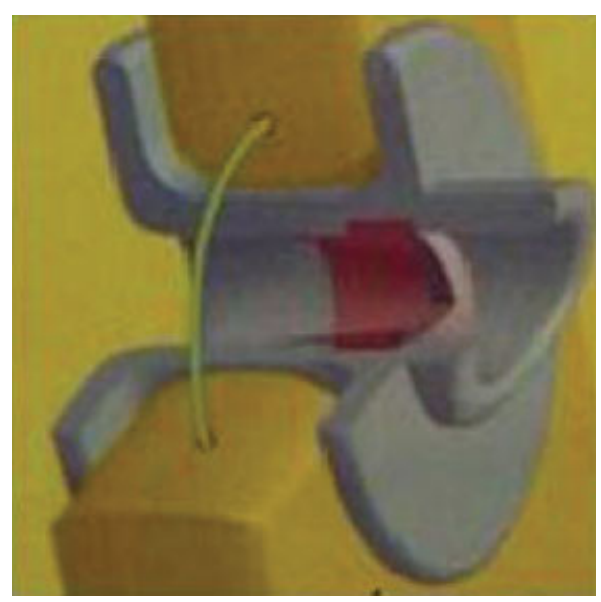

FIGURE 2. Position of purse-string. ${ }^{21}$ [Color figure can be viewed in the online issue, which is available at www.interscience. wiley.com.]

was difficult to reach the fistula, but in all the other patients the suture was easily applied.

The procedure was carried out in the day care facility in most patients. Immediately after placement of the suture, the patients could resume drinking and eating.

For procedures under local anesthesia, the patients were immediately tested for residual leakage while swallowing some water. At each following outpatient visit, this test was carried out.

Statistics. We assessed the time to recurrence of peripheral leakage over an average period of 19.4 months by means of the Kaplan-Meier method. ${ }^{25}$ Data were collected prospectively.

Using the date of application of the suture as starting point, the end point analyzed was the date of recurrence of leakage. We also assessed the time to recurrence of leakage intractable by simple measures such as prosthesis size modification, new purse-string suture, or granulation tissue removal. Patients with no recurrent leakage or dying during follow-up were censored at the last observation date. When after recurrence a second, third, or fourth purse-string suture was applied, we again assessed the time to recurrence. The presence of recurrent leakage at the fixed time points " 1 month" and " 1 year" was noted as well.

Our aim was to get the patients free of leakage without losing their voice prosthesis. From this, prospective results were classified as follows: (1) successful (objective reached), and (2) unsuccessful (closure of tracheoesophageal fistula required because of recurrent leakage).

\section{RESULTS}

One patient was excluded from the study, the procedure being impossible because the stoma was too small.

Immediately following the purse-string procedure, none of the patients showed residual leakage. No patient developed postoperative complications.

One month after application of the pursestring suture, 18 patients $(90 \%)$ were still free of leakage. Nine patients had a follow-up of more than 1 year, 4 of them ( $44 \%)$ showed no recurrent leakage at 1 year following the first purse-string procedure.

The procedure was successful in 16 patients $(80 \%)$ (Table 2). Peripheral leakage in each case stopped without loss of the voice prosthesis. One patient discontinued use of the prosthesis for reasons unrelated to leakage (inability to produce proper speech because of lack of motivation and dexterity). Her fistula was closed 4 months after placement of the sling suture, and at that point, she was censored.

Fifteen patients $(75 \%)$ had recurrent leakage 0.2 to 43 months (average, 5 months) after the suture (Figure 3). Of the 15 patients with recurrent leakage following the first purse-string suture, 4 patients $(27 \%)$ eventually underwent closure of the tracheoesophageal fistula for reasons of recurrent leakage, so here the suture sling was unsuccessful.

The other 11 patients did not have their tracheoesophageal fistula closed. In 10 of them, the leakage was amenable to simple measures: the leakage was treated with downsizing the voice prosthesis in 6 patients and with upsizing (peripheral leakage due to thickening and extrusion of

Table 2. Results of purse-string suture.

\begin{tabular}{lc}
\hline Results (mean follow-up 19.4 mo) & No. of patients \\
\hline Successful & 16 \\
No further leakage observed & 5 \\
Recurrent leakage amenable to & 11 \\
easy treatment & \\
Prosthesis size modification & 3 \\
2 purse-string sutures required & 5 \\
3 purse-string sutures required & 1 \\
4 purse-string sutures required & 1 \\
Granulation tissue removal & 1 \\
Unsuccessful & 4 \\
Closure of TEF required because & 3 \\
of recurrent leakage & \\
Failed because of tumor recurrence & 1 \\
\hline
\end{tabular}

Abbreviation: TEF, tracheoesophageal fistula. 


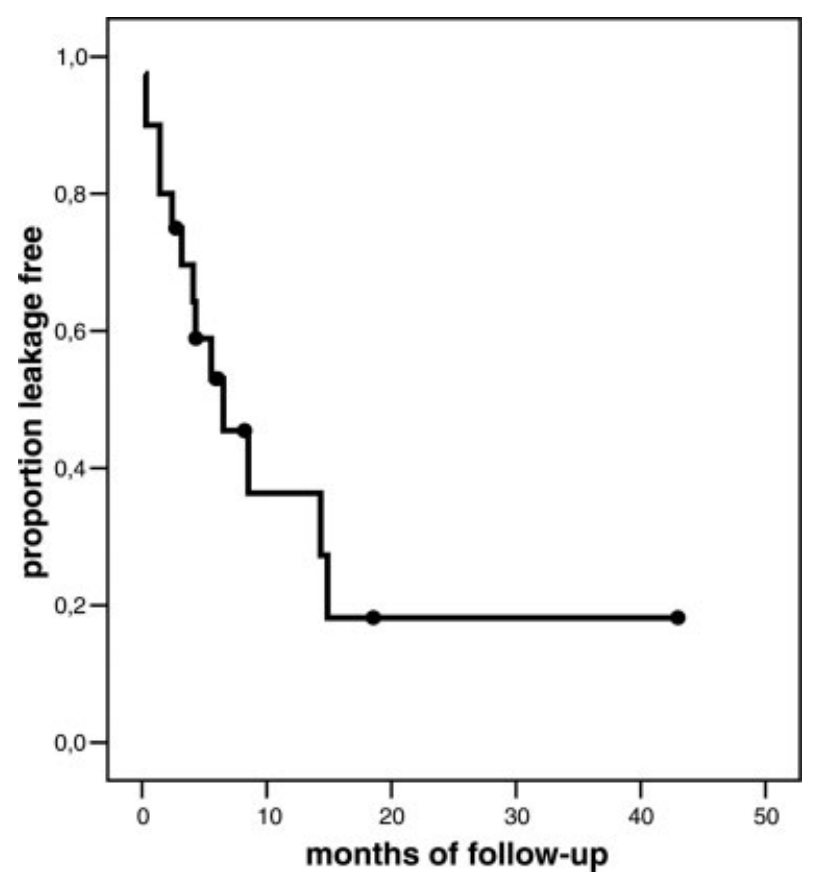

FIGURE 3. Leakage-free interval after first purse-string suture (in months). Bullets indicate censored observations.

the prosthesis) in 1 patient; in 2 patients a new purse-string suture was applied. One patient experienced recurrent leakage 15 months after the application of the sling suture due to some granulation tissue, which was easily removed. In 1 less fortunate patient, recurrent leakage was the first sign of tumor recurrence.

In total, 7 patients needed a second pursestring suture (either as a primary treatment of recurrent leakage or after a different treatment of the recurrence had failed), 2 needed a third, and 1 needed a fourth purse-string suture (Figure 4).

Overall, using a purse-string suture, and managing possible recurrent leakage by simple measures such as size modification and a repeat pursestring suture, 9 patients were still in follow-up and leakage free after 1 year; 7 patients had a follow-up of less than 1 year but were also leakage free, and 4 patients experienced intractable recurrent leakage (Figure 5).

\section{DISCUSSION}

Tracheoesophageal puncture with the insertion of a voice prosthesis has been widely applied following total laryngectomy. Although this is a highly successful procedure for voice restoration, complications are not uncommon and can be severe. Peripheral leakage of saliva or food around the pros-

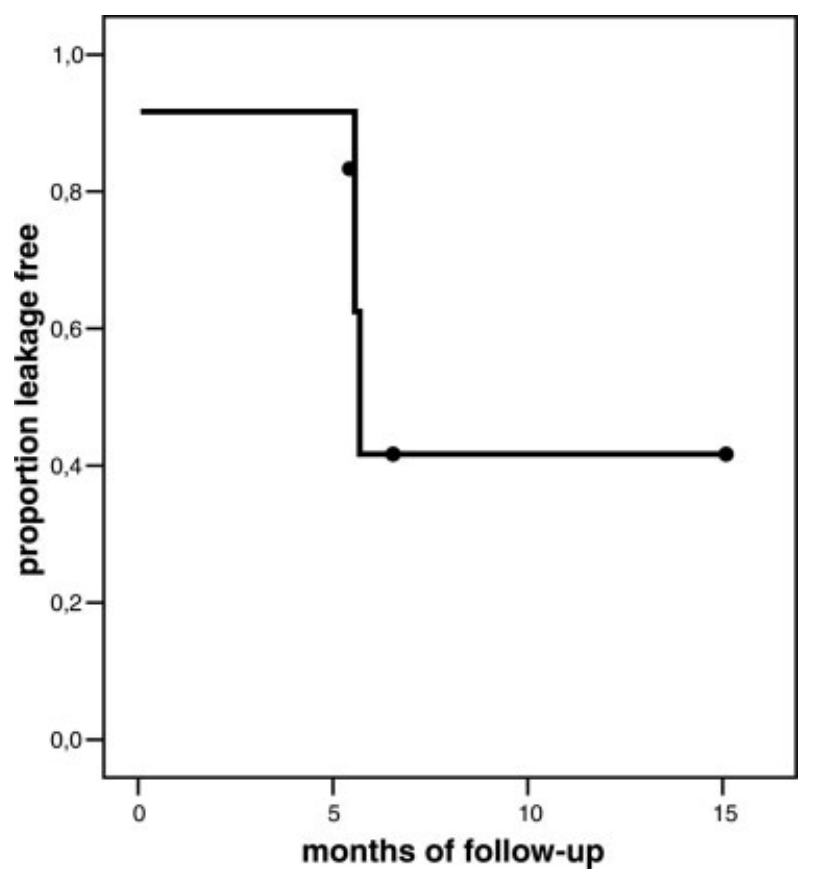

FIGURE 4. Leakage-free interval after second purse-string suture (in months). Bullets indicate censored observations.

thesis is 1 of the most annoying complications, sometimes intractable by conservative measures and requiring closure of the fistula. However, in patients with successful voice restoration by

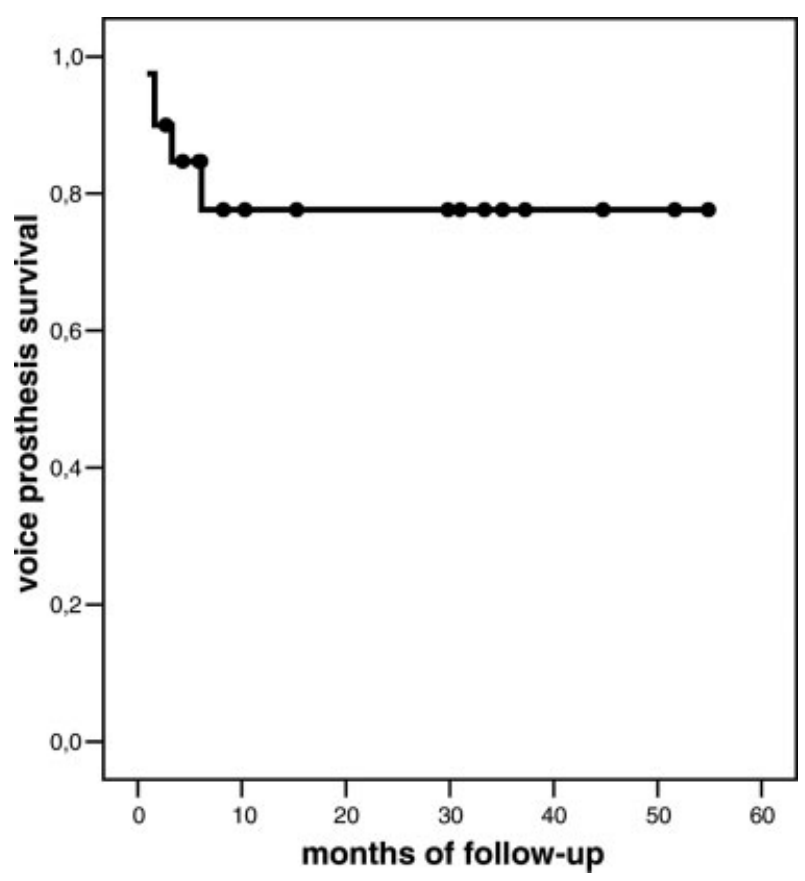

FIGURE 5. Proportion leakage-free using a purse-string suture and managing possible recurrent leakage with conservative treatment over time. Bullets indicate censored observations. 
means of the prosthesis, maintenance of the fistula is a priority.

The first measure to be taken is downsizing the voice prosthesis length. This will solve the problem in a number of cases. ${ }^{2,11}$

A second method consists of temporary removal of the prosthesis to allow the fistula to shrink, which is successful in $53 \%$ of the cases. ${ }^{11}$ The greatest disadvantage of this technique is that it requires hospital admission and nasogastric tube feeding for several days. Some authors report on cauterizing of the fistulous tract with silver nitrate or electrocautery. Wetmore et al mention this as a successful method in all of the 5 patients treated with it. ${ }^{12}$ Périé et al $^{8}$ suggest that this method would be less efficient following radiotherapy due to modification of microvascularization and fibrosis, altering the regeneration of tissue around the puncture site.

A third method is based on the increase of the tracheoesophageal wall thickness by means of injectable substances. The first product used for this purpose was Gax-collagen ${ }^{13}$ but because of relatively low success rates ${ }^{4,11}$ and the risk of transmission of Creutzfeldt-Jacob disease, it has been abandoned. Hylaform, a colorless viscoelastic gel, has been the next substance, but is expensive and has only been described in 1 case report. ${ }^{14}$ Autogenous fat injection was introduced by Laccourreye et $\mathrm{al}^{16}$ in a series of 7 patients. It was successful in 4 patients, 3 patients required secondary injections, and 2 of them ended up with surgical closure of the fistula. Extrusion of the autogenous fat was the only complication noted. Périé et $\mathrm{al}^{15}$ evaluated success rates of fat injection in a group of 10 patients and found complete improvement over 10 to 61 months in 6 patients ( 1 needed a second injection and 1 died of metastasis 6 months later). Fourteen cases of leakage intractable by downsizing or temporary removal of voice prosthesis have been successfully treated with injection of Bioplastique. ${ }^{17-19}$ However, in most cases there was a recurrence of peripheral leakage requiring a second injection 4 to 6 months after the procedure. Further experience with this product is needed. Granulocyte-macrophage colony-stimulating factor was injected in the fistula wall in 3 patients to increase fistula shrinkage. ${ }^{20}$ The advantage of this technique is that it can be used when the local tissue condition (diminished elasticity due to scarring) makes the introduction of a shorter voice prosthesis or a suture sling impossible. Disadvantages are the lack of experience, and the need for more than 1 injection in 2 of the 3 described cases. Surgical closure of the fistula is effective in most cases ${ }^{22}$ but should be avoided when good speech is obtained with the voice prosthesis.

The fourth option is the application of a submucosal purse-string suture. ${ }^{1,2,21}$ Until now, no success rates have been published. Peeters et $\mathrm{al}^{21}$ treated 13 patients with suture slings, using a resorbable suture (personal communication): in 10 patients this was successful; 6 of the successfully treated patients needed only 1 suture, 3 needed 2 sutures, and 1 needed 4 sutures. The number of hospital admissions for shrinkage decreased from 12 to 4 . These results are consistent with our observations of eventual leakage control in 16 of 20 treated patients. Advantages of the technique are the low cost, the possibility of application under local anesthesia, the short period of hospitalization required, the absence of adverse events, and the immediate relief of leakage. Local anatomy (small size of stoma) sometimes makes the procedure impossible, which we experienced in 1 patient.

\section{CONCLUSION}

Application of a submucosal purse-string suture appears to be a valuable procedure in the treatment of leakage around voice prostheses. We can recommend it in each patient who is nonresponsive to downsizing, because in most cases it is easy to perform (even under local anesthesia) and it has a substantial success rate, is cheap, does not require long hospitalization, and has no considerable side effects.

Acknowledgments. The authors sincerely thank Professor Alfons Balm, Department of Head and Neck Oncology and Surgery, The Netherlands' Cancer Institute, for his kind help in reviewing this manuscript.

\section{REFERENCES}

1. Hilgers FJM, Balm AJM, Gregor RT, et al. A practical guide to post-laryngectomy vocal and pulmonary rehabilitation. 4th ed. 2003; http://www.hoofdhalskanker.info/ Provoxweb/General_Introduction.htm.

2. Brown DH, Hilgers FJM, Irish JC, Balm AJM. Postlaryngectomy voice rehabiliatation: state of the art at the millenium. World J Surg 2003;27:824-831.

3. Ferrer Ramirez MJ, Guallart Domenech F, Brotons Durban S, Carrasco Llatas M, Estelles Ferriol E, Lopez Martinez R. Surgical voice restoration after total laryngectomy: long-term results. Eur Arch Otorhinolaryngol 2001;258:463-466. 
4. Op de Coul BM, Hilgers FJ, Balm AJ, Tan IB, van den Hoogen FJ, van Tinteren $\mathrm{H}$. A decade of postlaryngectomy vocal rehabilitation in 318 patients: a single institution's experience with consistent application of Provox indwelling voice prosthesis. Arch Otolaryngol Head Neck Surg 2000;126:1320-1328.

5. Wang RC, Bui T, Sauris E, Ditkoff M, Anand V, Klatsky IA. Long-term problems in patients with tracheoesophageal puncture. Arch Otolaryngol Head Neck Surg 1991; 117:1273-1276.

6. Laccourreye O, Menard M, Crevier-Buchman L, Couloigner V, Brasnu D. In situ lifetime, causes for replacement, and complications of the Provox voice prosthesis. Laryngoscope 1997;107:527-530.

7. Izdebski K, Reed CG, Ross JC. Problems with tracheoesophageal fistula voice restoration in totally laryngectomized patients. A review of 95 cases. Arch Otolaryngol Head Neck Surg 1994;120:840-845.

8. Andrews JC, Mickel RA, Hanson DG, Monahan GP, Ward PH. Major complications following tracheoesophageal puncture for voice rehabilitation. Laryngoscope 1987;97:562-567.

9. Trudeau MD, Schuller DE, Hall DA. The effects of radiation on tracheoesophageal puncture. Arch Otolaryngol Head Neck Surg 1989;115:1116-1117.

10. Eerenstein SEJ, Grolman W, Schouwenburg PF. Downsizing of voice prosthesis diameter in patients with laryngectomy. Arch Otolaryngol Head Neck Surg 2002;128: 838-841.

11. Brasnu D, Pages JC, Laccourreye O, Jouffre V, Monfrais Pfauwadel MC, Crevier Buchman L. Results of the treatment of spontaneous widening of tracheoesophageal punctures after laryngeal implant. Ann Otolaryngol Chir Cervicofac 1994;111:465-460.

12. Wetmore SJ, Johns ME, Baker SR. The Singer-Blom restoration procedure. Arch Otolaryngol 1981;107:674-676.

13. Remacle MJ, Declaye MD. Gax-collagen injection to correct an enlarged tracheoesophageal fistula for a vocal prosthesis. Laryngscope 1988;98:1350-1352.
14. Luff DA, Izzat S, Farrington WT. Viscoaugmentation as a treatment for leakage around the Provox2 voice rehabilitation system. J Laryngol Otol 1999;113:847848.

15. Périé S, Ming X, Dewolf E, Lacau St. Guily J. Autologous fat injection to treat leakage around tracheoesophageal puncture. Am J Otolaryngol 2002;23:345-350.

16. Laccourreye O, Papon JF, Brasnu D, Hans C. Autogenous fat injection for the incontinent tracheoesophageal puncture site. Laryngoscope 2002;112:1512-1514.

17. Rokade AV, Mathews J, Reddy KT. Tissue augmentation using Bioplastique ${ }^{\circledR}$ as a treatment of leakage around a Provox2 ${ }^{\circledR}$ voice prosthesis. J Laryngol Otol 2003;117:80_ 82.

18. Solans T, Merol JC, Chays A, Labrousse M. Treatment of voice prosthesis leakage. Preliminary results. Ann Otolaryngol Chir Cervicofac 2005;122:202-205.

19. Lorincz BB, Lichtenberger G, Bihari A, Falvai J. Therapy of periprosthetical leakage with tissue augmentation using Bioplastique around the implanted voice prostesis. Eur Arch Otorhinolaryngol 2005;262:32-34.

20. Margolin G, Masucci G, Kuylenstierna R, Bjorck G, Hertegard S, Karling J. Leakage around voice prosthesis in laryngectomees: treatment with local GM-CSF. Head Neck 2001;23:1006-1010.

21. Peeters AJGE, Vreeburg GCM, Hilgers FJM. Chirurgische behandeling van spraakbuttonlekkage. Nederlands tijdschr Geneesk 1996;140:1793-1794.

22. Rosen A, Scher N, Panje WR. Surgical closure of persisting failed tracheoesophageal voice fistula. Ann Otol Rhinol Laryngol 1997;106:775-778.

23. Hosal SA, Myers EU. How I do it: closure of tracheoesophageal puncture site. Head Neck 2001;23:214-216.

24. Delaere PR, Delsupehe KG. Closure of persistent tracheoesophageal fistulas after removal of the voice prosthesis. Laryngoscope 1994;104:494-496.

25. Kaplan EL, Meier P. Nonparametric estimation from incomplete observations. J Am Stat Ass 1958;53:457481. 